\title{
Johannes Kepler's Universe: Its Physics and Metaphysics
}

\section{Citation}

Holton, Gerald. 1956. Johannes Kepler's Universe: Its Physics and Metaphysics. American Journal of Physics 24, 340. https://doi.org/10.1119/1.1934225

\section{Permanent link}

http://nrs.harvard.edu/urn-3:HUL.InstRepos:37902459

\section{Terms of Use}

This article was downloaded from Harvard University's DASH repository, and is made available under the terms and conditions applicable to Other Posted Material, as set forth at http:// nrs.harvard.edu/urn-3:HUL.InstRepos:dash.current.terms-of-use\#LAA

\section{Share Your Story}

The Harvard community has made this article openly available.

Please share how this access benefits you. Submit a story.

\section{Accessibility}


Beyond that our responsibilities cannot be any greater than those of any other citizen. . . . I am confident that, whatever the scientists are able to discover or invent, the people will be good enough to control it for the benefit of everyone."

The charge has been laid upon us all. One might wish at this point that the veneer of civilization were just a little thicker. As a people, we now have before us perhaps the greatest opportunity in all human history to demonstrate that man can remain permanently civilized. May God grant us the intelligence to do it!

\title{
Johannes Kepler's Universe : Its Physics and Metaphysics
}

\author{
Geratd Holton \\ Harvard University, Cambridge, Massachusetts
}

(Received December 13, 1954)

\begin{abstract}
Though much neglected and misunderstood, Kepler was the first to attempt the detailed construction of a clockwork-like world picture operating on a single physical force law. An analysis of the eventual failure of Kepler's attempt gives us a clue to the central enigma in his writings: His heliocentric conception is a superposition of three aspects-physical, mathematical, and metaphysical. Kepler's free choice among these, which is the source both of his strength and of his apparent inconsistencies, results from his indecision between two different criteria of reality; according to one, the real world is the world of phenomena explainable by mechanical principles, and according to the other it is the world of harmonious regularity which man can discern by virtue of a direct connection existing between his mind and the Deity.
\end{abstract}

$T^{\mathrm{H}}$ HE important publications of Johannes Kepler (1571-1630) preceded those of Galileo, Descartes, and Newton in time, and in some respects they are even more revealing. And yet, Kepler has been strangely neglected and misunderstood. Very few of his voluminous writings have been translated into English. ${ }^{1}$ In this language there has been neither a full biography ${ }^{2}$ nor even a major essay on his work in over twenty years. Part of the reason lies in the apparent confusion of incongrouous elements-physics and metaphysics, astronomy and astrology, geometry and theology-which characterizes Kepler's work. Even in comparison with Galileo and Newton, Kepler's writings are strikingly different in the quality of preoccupation. He is more evidently rooted in a time when animism, alchemy, astrology, numerology, and witchcraft presented problems to be seriously argued. His

1 Books 4 and 5 of the Epitome of Copernican Astronomy, and Book 5 of the Harmonies of the World, in Great Books of the Western World (Encyclopedia Britannica, Chicago, 1952), Vol. 16.

2 The definitive biography is by the great Kepler scholar Max Caspar, Johannes Kepler (W. Kohlhammer, Stuttgart, 1950); an English translation is being prepared. A usefu short essay is in Johann Kepler, 1571-1630 (edited by the History of Science Society, Baltimore, 1931). mode of presentation is equally uninviting to modern readers, so often does he seem to wander from the path leading to the important questions of physical science. Nor is this impression merely the result of the inevitable astigmatism of our historical hindsight. We are trained on the ascetic standards of presentation originating in Euclid, as reestablished for example in Books I and II of Newton's Principia, ${ }^{3}$ and are taught to hide behind a rigorous structure the actual steps of discovery,--those guesses, errors, and occasional strokes of good luck without which creative scientific work does not usually occur. But Kepler's embarrassing candor and intense emotional involvement force him to give us a detailed account of his tortuous progress. He still allows himself to be so overwhelmed by the beauty and variety of the world as a whole that he cannot yet persistently limit his attention to the main problems which can in fact be solved. He gives us lengthy accounts of his failures, though some-

\footnotetext{
${ }^{3}$ But Newton's Opticks, particularly in the latter portions, is rather reminiscent of Kepler's style. In Book II, Part IV, Observation 5, there is, for example, an attempt to associate the parts of the light spectrum with the "Differences of the lengths of a monochord which sounds the tones in an eight.'
} 
times they are tinged with ill-concealed pride in the difficulty of his task. With rich imagination he frequently finds analogies from every phase of life, exalted or commonplace. He is apt to interrupt his scientific thoughts, either with exhortations to the reader to follow a little longer through the almost unreadable account, or with trivial side issues and textual quibbling, or with personal anecdotes or delighted exclamations about some new geometrical relation, a numerological or musical analogy. And sometimes he breaks into poetry or a prayer-indulging, as he puts it, in his "sacred ecstacy." We see him on his pioneering trek, probing for the firm ground on which our science could later build, and often led into regions which we now know to be unsuitable marshland.

These characteristics of Kepler's style are not merely idiosyncrasies. They mirror the manysided struggle attending the rise of modern science in the early 17 th century. Conceptions which we might now regard as mutually exclusive are found to operate side-by-side in his intellectual make-up. A primary aim of this essay is to identify those disparate elements, and to show that in fact much of Kepler's strength stems from their juxtaposition. We shall see that when his physics fails, his metaphysics comes to the rescue; when a mechanical model breaks down as a tool of explanation, a mathematical model takes over, and at its boundary in turn there stands a theological axiom. Kepler set out to unify the classical picture of the world, one which was split into celestial and terrestrial regions, through the concept of a universal physical force; but when this problem did not yield to physical analysis, he readily returned to the devices of a unifying image, namely the central sun ruling the world, and of a unifying principle, that of all-pervading mathematical harmonies. In the end he failed in his initial project of providing the mechanical explanation for the observed motions of the planets; but he succeeded at least in throwing a bridge from the old view of the world as unchangeable cosmos to the new view of the world as the playground of dynamic and mathematical laws. And in the process he turned up, as if it were by accident, those clues which Newton needed for the eventual establishment of the new view.

\section{TOWARD A CELESTIAL MACHINE}

$A$ sound instinct for physics and a commitment to neo-Platonic metaphysics,- - these are Kepler's two main guides which are now to be examined separately and at their point of merger. As to the first, Kepler's genius in physics has often been overlooked by critics who were taken aback by his frequent excursions beyond the bounds of science as they came to be understood later, although his Dioptrice (1611) and his mathematical work on infinitesimals (in Nova Stereometria, 1615 ) and on logarithms (Chilias Logarithmorum, 1624) have direct appeal for the modern mind. But even Kepler's casually delivered opinions of ten prove his insight beyond the general state of knowledge of his day. One example is his creditable treatment of the motion of projectiles on the rotating earth, equivalent to the formulation of the superposition principle of velocities (letter to David Fabricius, October 11, 1605). Another is his opinion of the perpetuum mobile:

"As to this matter, I believe one can prove with very good reasons that neither any never-ending motion nor the quadrature of the circle-two problems which have tortured great minds for ages - will ever be encountered or offered by nature."

But of course, on a large scale, Kepler's genius lies in his early search for a physics of the solar system. He is the first to look for a universal physical law based on terrestrial mechanics to comprehend the whole universe in its quantitative details. In the Aristotelian and Ptolemaic world scheme, and indeed in Copernicus' own, the planets moved in their respective orbits by laws which were either purely mathematical or mechanical in a nonterrestrial sense. As Goldbeck

Letter of Herwart von Hohenburg, March 26, 1598, i.e. seven years before Stevinus implied the absurdity of perpetual motion in the Hypomnemala Mathematica (Leyden, 1605). Some of Kepler's most important letters are collected in Max Caspar and Walther von Dyck Johannes Kepler in seinen Briefen (R. Oldenbourg, Munich and Berlin, 1930). A more complete collection in the original languages is to be found in Vols. 13-15 of the modern edition of Kepler's collected works, edited by W. von Dyke and $M$. Caspar (Beck, Munich, 1937 and later). In the past, these letters appear to have received insufficient attention in the study of Kepler's work and position. (The present English translations of all quotations from them are the writer's.) Excerpts from some letters were also translated by Carola Baumgardt, Johannes Kepler (Philosophical Library, Inc., New York, 1951). 
reminds us, ${ }^{5}$ Copernicus himself still warned to keep a clear distinction between celestial and merely terrestrial phenomena "so as not to attribute to the celestial bodies what belongs to the earth." This crucial distinction disappears in Kepler from the beginning. In his youthful work of 1596, the Mysterium Cosmographicum, a single geometrical device is used to show the necessity of the observed orbital arrangement of all planets. In this respect, the earth is treated as being an equal of the other planets. ${ }^{6}$ In the words of Otto Bryk, ${ }^{7}$

"The central and permanent contribution lies in this, that for the first time the whole world structure was subjected to a single law of construction,- - though not a force law such as revealed by Newton, and only a noncausative relationship between spaces, but nevertheless one single law."

Four years later Kepler meets Tycho Brahe and from him learns to respect the power of precise observation. The merely approximate agreement between the observed astronomical facts and the scheme laid out in the Mysterium Cosmographicum is no longer satisfying. To be sure, Kepler always remained fond of this work, and in the Dissertatio cum Nuncio Sidereo (1610) even hoped that Galileo's newly-found moons of Jupiter would help to fill in one of the gaps left in his geometrical model. But with another part of his being Kepler knows that an entirely different approach is wanted. And here Kepler turns

${ }^{5}$ Ernst Goldbeck, "Abhandlungen zur Philosophie und ihrer Geschichte," in Kepler's Lehre von der Gravitation (Max Niemeyer, Halle, 1896), Vol. 6; a useful monograph demonstrating Kepler's role as a herald of mechanical astronomy. The reference is to De Revolutionibus, first edition, p. 3.

'In Kepler's Preface to his Dioptrice (1611) he calls his early Mysterium Cosmographicum "a sort of combination of astronomy and Euclid's Geometry," and describes the main features as follows: "I took the dimensions of the planetary orbits according to the astronomy of Copernicus, who makes the sun immobile in the center, and the earth movable both round the sun and upon its own axis; and I showed that the differences of their orbits corresponded to the five regular Pythagorean figures, which had been already distributed by their author among the elements of the world, though the attempt was admirable rather than happy or legitimate . . . The scheme of the five circumscribed regular bodies originally represented to Kepler the cause of the observed number (and orbits) of the planets: "Habes rationem numeri planetarium."

'Otto J. Bryk, translator and editor, Johann Kepler, Die Zusammenklange der Welten (Diederichs, Jena, 1918), p. xxiii. to the new conception of the universe. While working on the Astronomia Nova, Kepler lays out his program:

"I am much occupied with the investigation of the physical causes. My aim in this is to show that the celestial machine is to be likened not to a divine organism but rather to a clockwork . . . , insofar as nearly all the manifold movements are carried out by means of a single, quite simple magnetic force, as in the case of a clockwork all motions [are caused] by a simple weight. Moreover I show how this physical conception is to be presented through calculation and geometry." 8

The celestial machine, driven by a single terrestrial force, in the image of a clockwork! This is indeed a prophetic goal. Published in 1609 , the Astronomia Nova significantly bears the subtitle Physica Coelestis. The book is best known for containing Kepler's First and Second Laws of planetary motion, but it represents primarily a search for one universal force law to explain the motions of planets-Mars in particular-as well as gravity and the tides. This breathtaking conception of unity is perhaps even more striking than Newton's, for the simple reason that Kepler had no predecessor.

\section{THE PHYSICS OF THE CELESTIAL MACHINE}

Kepler's first recognition is that forces between bodies are caused not by their relative positions or their geometrical arrangements, as was accepted by Aristotle, Ptolemy, and Copernicus, but by mechanical interactions between the material objects. Already in the Mysterium Cosmographicum (Chap. XVII) he announced "Nullum punctum, nullum centrum grave est," and he gave the example of the attraction between a magnet and a piece of iron. In William Gilbert's De Magnete (1600), published four years later, Kepler finds a careful explanation that the action of magnets seems to come from pole points, but must be attributed to the parts of the body, not the points.

${ }^{8}$ Letter to Herwart von Hohenburg, February 10, 1605. At about the same time he writes in a similar vein to Christian Severin Longomontanus concerning the relation of astronomy and physics: "I believe that both sciences are so closely interlinked that the one cannot attain completion without the other." 
In the spirited "Objections" which Kepler appended to his own translation of Aristotle's

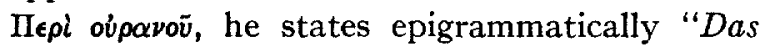
Mittele is nur ein Dupffin," and he elaborates as follows:

"How can the earth, or its nature, notice, recognise and seek after the center of the world which is only a little point [Düpfflin] -and then go toward it? The earth is not a hawk, and the center of the world not a little bird; it [the center] is also not a magnet which could attract the earth, for it has no no substance and therefore cannot exert a force."

In the Introduction to the Astronomia Nova, which we shall now consider in some detail, Kepler is quite explicit:

"A mathematical point, whether it be the center of the world or not, cannot move and attract a heavy object .... . Let the [Aristotelian] physicists prove that such a force is to be associated with a point, one which is neither corporeal nor recognisable as anything but a pure reference [mark]."

Thus what is needed is a "true doctrine concerning gravity"; the axioms leading to it include the following:

"Gravitation consists in the mutual bodily striving among related bodies toward union or connection; (of this order is also the magnetic force)."

This premonition of universal gravitation is by no means an isolated example of lucky intuition. Kepler's feeling for the physical situation is admirably sound, as shown in additional axioms :

"If the earth were not round, a heavy body would be driven not everywhere straight toward the middle of the earth, but toward different points from different places.

"If one were to transport two stones to any arbitrary place in the world, closely together but outside the field of force [extra orbe virtutis] of a third related body, then those stones would come together at some intermediate place similar to two magnetic bodies, the first approaching the second through a distance which is proportional to the mass [moles] of the second."

And after this precursor of the principle of conservation of momentum, there follows the first attempt at a good explanation for the tides in terms of a force of attraction exerted by the moon.

But the Achilles heel of Kepler's celestial physics is found in the very first "axiom," in his Aristotelian conception of the law of inertia, where inertia is identified with a tendency to come to rest-causa privativa motus:

"Outside the field of force of another related body, every bodily substance, insofar as it is corporeal, by nature tends to remain at the same place at which it finds itself." 9

This axiom deprives him of the concepts of mass and force in useful form, - the crucial tools needed for shaping the celestial metaphysics of the ancients into the celestial physics of the moderns. Without these concepts, Kepler's world machine is doomed. He has to provide separate forces for the propulsion of planets tangentially along their paths and for the radial component of motion.

Moreover, he assumed that the force which reaches out from the sun to keep the planets in tangential motion falls inversely with the increasing distance. The origin and the consequences of this assumption are very interesting. In Chap. 20 of the Mysterium Cosmographicum, he speculated casually why the sidereal periods of revolution on the Copernican hypothesis should be larger for the more distant planets, and what force law might account for this:

"We must make one of two assumptions: either the forces of motion [animae motrices] [are inherent in the planets] and are feebler the more remote they are from the sun, or there is only one anima motrix at the center of the orbits, that is, in the sun. It drives the more vehemently the closer the [moved]

- Previously, Kepler discussed the attraction of the moon in a letter to Herwart, January 2,1607 . The relative motion of two isolated objects and the concept of inertia are treated in a letter to D. Fabricius, October 11, 1605. On the last subject, see A. Koyre, Phil. Rev. 52, 344-345 (1943). 
body lies; its effect on the more distant bodies is reduced because of the distance [and the corresponding] decrease of the impulse. Just as the sun contains the source of light and the center of the orbits, even so can one trace back to this same sun life, motion and the soul of the world .... Now let us note how this decrease occurs. To this end we will assume, as is very probable, that the moving effect is weakened through spreading from the sun in the same manner as light."

This suggestive image-with its important overtones which we shall discuss below-does, however, not lead Kepler to the inverse-square law of force, for he is thinking of the spreading of light in a plane, corresponding to the plane of planetary orbits. The decrease of light intensity is therefore associated with the linear increase in circumference for more distant orbits! In his pre-Newtonian physics, where force is proportional not to acceleration but to velocity, Kepler finds a ready use for the inverse firstpower law of gravitation. It is exactly what he needs to explain his observation that the speed of a planet in its elliptical orbit decreases linearly with the increase of the planet's distance from the sun. Thus Kepler's Second Law of Planetary Motion-which he actually discovered before the so-called First and Third laws-finds a partial physical explanation in joining several erroneous postulates.

In fact, it is clear from the context that these postulates originally suggested the Second Law to Kepler. ${ }^{10}$ But not always is the final outcome so happy. Indeed, the hypothesis concerning the physical forces acting on the planet seriously delays Kepler's progress toward the law of elliptical orbits (First Law). Having shown that "the path of the planet [Mars] is not a circle but an oval figure," he attempts (Chap. 45, Astronomia Nova) to find the details of a physical force law which would explain the "oval" path in a

\footnotetext{
${ }^{10}$ Not only the postulates but also some of the details of their use in the argument were erroneous. For a short discussion of this concrete illustration of Kepler's use of physics in astronomy, see J. L. E. Dreyer, History of the Planetary System from Thales to Kepler (Dover Publications, New York, 1953), second edition, pp. 387-399. A longer discussion is in Max Caspar's introductory material to his edition of the Astronomia Nova (R. Oldenbourg, Munich and Berlin, 1929).
}

quantitative manner. But after ten chapters of tedious work he has to confess that "the physical causes in the 45th chapter thus go up in smoke." Then in the remarkable 57 th chapter, a final and rather desperate attempt is made to formulate a force law. Kepler even dares to entertain the notion of combined magnetic influences and animal forces (via animali) in the planetary system. Of course, the attempt fails. The accurate clockwork-like celestial machine cannot be constructed.

To be sure, Kepler does not give up his conviction that a universal force exists in the universe, akin to magnetism. For example, in Book 4 of the Epitome of Copernican Astronomy (1620), we encounter the picture of a sun as a spherical magnet with one pole at the center and the other distributed over its surface. Thus a planet, itself magnetized like a bar magnet with a fixed axis, is alternately attracted to and repelled from the sun in its elliptical orbit. This is to explain the radial component of planetary motion. The tangential motion has been previously explained (in Chap. 34, Astronomia Nova) as resulting from the drag or torque which magnetic lines of force from the rotating sun are supposed to exert on the planet as they sweep over it. But the picture remains qualitative and incomplete, and Kepler does not return to his original plan to "show how this physical conception is to be presented through calculation and geometry." 8 Nor does his long labor bring him even a fair amount of recognition. Galileo introduces Kepler's work into his discussion on the world systems only to scoff at Kepler's notion that the moon affects the tides," even though Tycho Brahe's data and Kepler's work based on them had shown that the Copernican scheme which Galileo was so ardently upholding did not correspond to the experimental facts of planetary motion. And Newton manages to remain strangely silent about Kepler throughout Books I and II of the Principia, by introducint the Third Law anonymously as "the phenomenon of the $\frac{3}{2}$ th power" and the First and Second Laws as "the Copernican hypothesis."12

1 Dialogue on the Great World Systems, edited by Giorgio de Santillana (University of Chicago Press, Chicago, 1953), p. 469. However, an oblique compliment to Kepler's Third Law may be intended in a passage on p. 286.

12 Principia edited by $\mathrm{F}$. Cajori (University of California Press, Berkeley, 1946), pp. 394-395. In Book III, Newton remarks concerning the fact that the Third Law 
Kepler's three laws have come to be treated as essentially empirical rules. How far removed this achievement was from his original ambition!

\section{KEPLER'S FIRST CRITERION OF REALITY: THE PHYSICAL OPERATIONS OF NATURE}

Let us now set aside for a moment the fact that Kepler failed to build a mechanical model of the universe, and ask why he undertook the task at all. The answer is that Kepler (rather like Galileo) was trying to establish a new philosophical interpretation for "reality." Moreover, he was quite aware of the novelty and difficulty of the task.

In his own words, Kepler wanted to "provide a philosophy or physics of celestial phenomena in place of the theology or metaphysics of Aristotle."18 Kepler's contemporaries generally regarded his intention of putting laws of physics into astronomy as a new and probably pointless idea. Even Michael Mastlin, Kepler's own beloved teacher, who had introduced Kepler to the Copernican theory, wrote him:

"Concerning the motion of the moon you write you have traced all the inequalities to physical causes; I do not quite understand this. I think rather that here one should leave physical causes out of account, and should explain astronomical matters only according to astronomical method with the aid of astronomical, not physical, causes and hypotheses. That is, the calculation demands astronomical bases in the field of geometry and arithmetic ....".14

applies to the moons of Jupiter: "This we know from astronomical observations." At last, on page 404, Kepler is credited with having "first observed" that the $\frac{3}{2}$ power law applies to the "five primary planets" and the earth. Newton's real debt to Kepler was best summarized in his own letter to Halley, July 14, 1686: "But for the duplicate proportion [the inverse-square law of gravitation] I can affirm that I gathered it from Kepler's theorem about twenty years ago."

1s Letter to Johann Brengger, October 4, 1607. This picture of a man struggling to emerge from the largely Aristotelian tradition is perhaps as significant as the usual one of Kepler as Copernican in a Ptolemaic world. Nor was Kepler's opposition, strictly speaking, Ptolemaic any longer. For this we have Kepler's own opinion (Harmonice Mundi, Book 3): "First of all, readers should take it for granted that among astronomers it is nowadays agreed that all planets circulate around the sun ...." meaning of course the system not of Copernicus but of Tycho Brahe, in which the earth was fixed and the moving sun served as center of motion for the other planets.

${ }^{14}$ Letter of October 1, 1616.
The difference between Kepler's conception of the "physical" problems of astronomy and the methodology of his contemporaries reveals itself clearly in the juxtaposition of representative letters by the two greatest astronomers of the time-Tycho Brahe and Kepler himself. Tycho, writing to Kepler (December 9,1599) repeats the preoccupation of two millenia of astronomical speculations:

"I do not deny that the celestial motions achieve a certain symmetry [through the Copernican hypothesis], and that there are reasons why the planets carry through their revolutions around this or that center at different distances from the earth or the sun. However, the harmony or regularity of the scheme is to be discovered only a posteriori . . . And even if it should appear to some puzzled and rash fellow that the superposed circular movements on the heavens yield sometimes angular or other figures, mostly elongated ones, then it happens accidently, and reason recoils in horror from this assumption. For one must compose the revolutions of celestial objects definitely from circular motions; otherwise they could not come back on the same path eternally in equal manner, and an eternal duration would be impossible, not to mention that the orbits would be less simple, and irregular, and unsuitable for scientific treatment."

This manifesto of ancient astronomy might indeed have been subscribed to by Pythagoras, Plato, Aristotle, and Copernicus himself. Against it, Kepler maintains a new stand. Writing to D. Fabricius (August 1, 1607), he sounds the great new leitmotif of astronomy: "The difference consists only in this, that you use circles, I use bodily forces." And in the same letter, he defends his use of the ellipse in place of the superposition of circles to represent the orbit of Mars:

"When you say it is not to be doubted that all motions occur on a perfect circle, then this is false for the composite, i.e., the real motions. According to Copernicus, as explained, they occur on an orbit distended at the sides, whereas according to Ptolemy and Brahe on spirals. But if you speak of components of motion, then you speak of 
something existing in thought, i.e., something that is not there in reality. For nothing courses on the heavens except the planetary bodies themselves, - no orbs, no epicycles ...."

This straightforward and modern-sounding statement implies that behind the word "real" stands "mechanical," that for Kepler the real world is the world of objects and of their mechanical interactions in the sense which Newton used, e.g., in the preface to the Principia:

"Then from these [gravitational] forces, by other propositions which are also mathematical, I deduce the motions of the planets, the comets, the moon, and the sea. I wish we could derive the rest of the phenomena of nature by the same kind of reasoning from mechanical principles . . . ."15

Thus we are tempted to see Kepler as a natural philosopher of the mechanistic-type later identified with the Newtonian disciples. But this is deceptive. Particularly after the failure of the program of the Astronomia Nova, another aspect of Kepler asserted itself. Though he does not appear to have been conscious of it, he never resolved finally whether the criteria of reality are to be sought on the physical or the metaphysical level. The words "real" or "physical" themselves, as used by Kepler, carry two interpenetrating complexes of meaning. Thus on receiving Mästlin's letter ${ }^{14}$ of October 1, 1616, Kepler jots down in the margin his own definition of "physical":

"I call my hypotheses physical for two reasons .... My aim is to assume only those things of which I do not doubt they are real and consequently physical, where one must refer to the nature of the heavens, not the elements. When I dismiss the perfect excentric and the epicycle, I do so because they are purely geometrical assumptions, for which a corresponding body in the heavens does not exist. The second reason for my calling my hypotheses physical is this ... I prove that the irregularity of the motion [of planets] corresponds to the nature of the planetary sphere, i.e., is physical."

\footnotetext{
${ }^{16}$ See reference 12 , p. xviii.
}

This throws the burden on the nature of heavens, the nature of bodies. How, then, is one to recognize whether a postulate or conception is in accord with the nature of things?

This is the main question, and to it Kepler has at the same time two very different answers, emerging, as it were, from the two parts of his soul. We may phrase one of the two answers as follows: The physically real world, which defines the nature of things, is the world of phenomena explainable by mechanical principles. This can be called Kepler's first criterion of reality, and assumes the possibility of formulating a sweeping and consistent dynamics which Kepler only sensed but which was not to be given until Newton's Principia. Kepler's other answer, to which he keeps returning again and again as he finds himself rebuffed by the deficiencies of his dynamics, and which we shall now examine in detail, is this: The physically real world is the world of mathematically expressed harmonies which man can discover in the chaos of events.

\section{KEPLER'S SECOND CRITERION OF REALITY: THE MATHEMATICAL HARMONIES OF NATURE}

Kepler's failure to construct a Physica Coelestis did not damage his conception of the astronomical world. This would be strange indeed in a man of his stamp if he did not have a ready alternative to the mechanistic point of view. Only rarely does he seem to have been really uncomfortable about the poor success of the latter, as when he is forced to speculate how a soul or an inherent intelligence would help to keep a planet on its path. Or again, when the period of rotation of the sun which Kepler had postulated in his physical model proved to be very different from the actual rotation as first observed through the motion of sunspots, Kepler was characteristically not unduly disturbed. The truth is that despite his protestations, Kepler was not as committed to mechanical explanations of celestial phenomena as was, say, Newton. He had another route open to him.

His other criterion, his second answer to the problem of physical reality, stemmed from the same source as his original interest in astronomy and his fascination with a universe describable in mathematical terms, namely from a frequently acknowledged metaphysics rooted in Plato and 
neo-Platonists such as Proclus Diadochus. It is the criterion of harmonious regularity in the descriptive laws of science. One must be careful not to dismiss it either as just a reappearance of an old doctrine or as an aesthetic requirement which is still recognized in modern scientific work; Kepler's conception of what is "harmonious" was far more sweeping and important than either.

A concrete example is again afforded by the Second Law, the "Law of Equal Areas." To Tycho, Copernicus, and the great Greek astronomers, the harmonious regularity of planetary behavior was to be found in the uniform motion in component circles. But Kepler recognized the orbits-after a long struggle-as ellipsi on which planets move in a nonuniform manner. The figure is lopsided. The speed varies from point to point. And yet, nestled within this double complexity is hidden a harmonious regularity which transports its ecstatic discoverer, - namely the fact that a constant area is swept out in equal intervals by a line from the focus of the ellipse, where the sun is, to the planet on the ellipse. For Kepler, the law is harmonious in three separate senses.

First, it is in accord with experience. Whereas Kepler, despite long and hard labors, had been unable to fit Tycho's accurate observations on the motion of Mars into a classical scheme of superposed circles, the postulate of an elliptical path fitted the observations at once. Kepler's dictum was: "harmonies must accomodate experience."16 How difficult it must have been for Kepler, a Pythagorean to the marrow of his bones, to forsake circles for ellipsi! For a mature scientist to find in his own work the need for abandoning his cherished and ingrained preconceptions, the very basis of his previous scientific work, in order to fulfill the dictates of quantitative experience,- - this was perhaps one of the great sacrificial acts of modern science, equivalent in recent scientific history to the agony of Max Planck. Kepler clearly drew the strength for this act from the belief that it would help him to gain an even deeper insight into the harmony of the world.

The second reason for regarding the law as

${ }^{16}$ Quoted in Weltharmonik, edited by Max Caspar (R. Oldenbourg, Munich and Berlin, 1939), p. 55*. harmonious is its reference to, or discovery of, a constancy,-although no longer a constancy simply of angular velocity but of areal velocity. The typical law of ancient physical science had been Archimedes' law of the lever: a relation of direct observables in static configuration. Even the world systems of Copernicus and of Kepler's Mysterium Cosmographicum still had lent themselves to visualization in terms of a set of fixed concentric spheres. And we recall that Galileo never made use of Kepler's ellipsi, but remained to the end a true follower of Copernicus who had said "the mind shudders" at the supposition of noncircular nonuniform celestial motion, and "it would be unworthy to suppose such a thing in a Creation constituted in the best possible way."

With Kepler's First Law and the postulation of elliptical orbits, the old simplicity was destroyed. The Second and Third Laws established the physical law of constancy as an ordering principle in a changing situation. Like the concepts of momentum and caloric in later laws of constancy, areal velocity itself is a concept far removed from the immediate observables. It was therefore a bold step to search for harmonies beyond both perception and preconception.

Thirdly, the law is harmonious also in a grandiose sense : the fixed point of reference in the law of equal areas, the "center" of planetary motion, is the center of the sun itself, whereas even in the Copernican scheme the sun was a little off the center of planetary orbits. With this discovery Kepler makes the planetary system at last truly heliocentric, and thereby satisfies his instinctive and sound demand for some material object as the "center" to which ultimately the physical effects that keep the system in orderly motion must be traced.

For Kepler, the last of these three points is particularly exciting. The sun as its fixed and commanding position at the center of the planetary system matches the picture which always rises behind Kepler's tables of tedious data, -the picture of a centripetal universe, directed toward and guided by the sun in its manifold roles: as the mathematical center in the description of celestial motions; as the central physical agency for assuring continued motion; and above all as the metaphysical center, the temple of the 
Deity. The three roles are in fact inseparable. For granting the special simplicity achieved in the description of planetary motions in the heliocentric system, as even Tycho was willing to grant, and assuming also that each planet must experience a force to drag it along its own constant and eternal orbit, as Kepler no less than the Scholastics thought to be the case, then it follows that the common need is supplied from what is common to all orbits, i.e., their common center; and this source of eternal constancy itself must be constant and eternal. Those however, are precisely the unique attributes of the Deity.

Using his characteristic method of reasoning on the basis of archetypes, Kepler piles further consequences and analogies on this argument. The most famous is the comparison of the worldsphere with the Trinity: the sun, being at the center of the sphere and thereby antecedent to its two other attributes, namely surface and volume, is compared to God the Father. With variations the analogy occurs many times throughout Kepler's writings, including many of his letters. The image haunts him from the very beginning (e.g., Chap. II, Mysterium Cosmographicum) and to the very end. Clearly, it is not sufficient to dismiss it with the usual phrase "sunworship."17 At the very least, one would have to allow that the exuberant Kepler is a worshipper of the whole solar system in all its parts.

The power of the sun-image can be traced to the acknowledged influence on Kepler by neoPlatonists such as Proclus (5th century) and Witelo (13th century). At the time it was current neo-Platonic doctrine to identify light with "the source of all existence" and to hold that "space and light are one." ${ }^{18}$ Indeed, one of the main preoccupations of the 16 th century neo-Platonists had been, to use a modern term, the transformation properties of space, light, and soul. Kepler's discovery of a truly heliocentric system is not

${ }^{17}$ E.g., E. A. Burtt, The Metaphysical Foundations of Modern Science (Routledge and Kegan Paul, London, 1932), p. $47 \mathrm{ff}$.

18 For a recent analysis of neo-Platonic doctrine, which regrettably omits a detailed study of Kepler, see Max Jammer, Concepts of Space (Harvard University Press, Cambridge, 1954), p. 37 ff. Neo-Platonism in relation to Kepler is discussed by Thomas Kuhn, The Copernican Revolution: Planetary Astronomy in Western Thought (in preparation). only in perfect accord with the conception of the sun as a ruling entity, but allows him, for the first time, to focus attention on the sun's position through argument from physics.

In the medieval period the "place" for God, both in Aristotelian and in neo-Platonic astronomical metaphysics, had commonly been either beyond the last celestial sphere or else all of space; for only those alternatives provided for the Deity a "place" from which all celestial motions were equivalent. But Kepler can adopt a third possibility: in a truly heliocentric system God can be brought back into the solar system itself, so to speak, enthroned at the fixed and common reference object which coincides with the source of light and with the origin of the physical forces holding the system together. In the De Revolutionibus Copernicus had glimpsed part of this image when he wrote, after describing the planetary arrangement,

"In the midst of all, the sun reposes, unmoving. Who, indeed, in this most beautiful temple would place the light-giver in any other part than that whence it can illumine all other parts?"

But Copernicus and Kepler were quite aware that the Copernican sun was not quite "in the midst of all"; hence Kepler's delight when, as one of his earliest discoveries, he found that the orbital planes of all planets intersect at the sun.

The threefold implication of the heliocentric image as mathematical, physical, and metaphysical center helps to explain the spell it casts on Kepler. As Wolfgang Pauli has pointed out in a highly interesting discussion of Kepler's work as a case study in "the origin and development of scientific concepts and theories," here lies the motivating clue: "It is because he sees the sun and planets against the background of this fundamental image [archetypische Bild] that he believes in the heliocentric system with religious fervor"; it is this belief "which causes him to search for the true laws concerning the proportion in planetary motion. . . ."19

\footnotetext{
${ }^{19}$ W. Pauli, "Der Einfluss archetypischer Vorstellungen auf die Bildung naturwissenschaftlicher Theorien bei Kepler," in Naturerklärung und Psyche, C. G. Jung and W. Pauli (Rascher, Zürich, 1952), p. 129. A pending English translation of the book has been announced by Pantheon Press under the title The Interpretation of Nature and the Psyche.
} 
To make the point succinctly, we may say that in its final version Kepler's physics of the heavens is heliocentric in its kinematics, but theocentric in its dynamics, where harmonies based in part on the properties of the Deity serve to supplement physical laws based on the concept of specific quantitative forces. This brand of physics is most prominent in Kepler's last great work, the Harmonice Mundi (1619). There the so-called Third Law of planetary motion is announced without any attempt to deduce it from mechanical principles, whereas in the Astronomia Nova magnetic forces had drivenno, obsessed-the planets. As in his earliest work, he shows that the phenomena of nature exhibit underlying mathematical harmonies. Having not quite found the mechanical gears of the world machine, he can at least give its equations of motion.

\section{THE SOURCE OF KEPLER'S HARMONIES}

Unable to identify Kepler's work in astronomy with physical science in the modern sense, many have been tempted to place him on the other side of the imaginary dividing line between classical and modern science. Is it after all, such a large step from the harmonies which the ancients found in circular motion and rational numbers to the harmonies which Kepler found in elliptical motions and exponential proportions? Is it not merely a generalization of an established point of view? Both answers are in the negative. For the ancients and for most of Kepler's contemporaries, the hand of the Deity was revealed in nature through laws which, if not qualitative, were harmonious in an essentially self-evident way; the axiomatic simplicity of circles and spheres and integers itself proved their deistic connection. But Kepler's harmonies reside in the very fact that the relations are quantitative, not in some specific simple form of the quantitative relations.

It is exactly this shift which we can now recognize as one point of breakthrough toward the later, modern conception of mathematical law in science. Where in classical thought the quantitative actions of nature were limited by a few necessities, the new attitude, whatever its metaphysical motivation, opens the imagination to an infinity of possibilities. As a direct consequence, where in classical thought the quantitative results of experience were used largely to fill out a specific pattern by a priori necessity, the new attitude permits the results of experience to reveal in themselves whatever pattern nature has in fact chosen from the infinite set of possibilities. Thus the seed is planted for the general view of most modern scientists, who find the world harmonious in a vague aesthetic sense because the mind can find, inherent in the chaos of events, order framed in mathematical laws - of whatever form they may be. As has been aptly said about Kepler's work:

"Harmony resides no longer in numbers which can be gained from arithmetic without observation. Harmony is also no longer the property of the circle in higher measure than the ellipse. Harmony is present when a multitude of phenomena is regulated by the unity of a mathematical law which expresses a cosmic idea." 20

Perhaps it was inevitable in the progress of modern science that the harmony of mathematical law should now be sought in aesthetics rather than in metaphysics. But Kepler himself would have been the last to propose or accept such a generalization. The ground on which he postulated that harmonies reside in the quantitative properties of nature lies in the same metaphysics which helped him over the failure of his physical dynamics of the solar system. Indeed, the source is as old as natural philosophy itself : the association of quantity per se with Deity. Moreover, as we can now show, Kepler held that man's ability to discover harmonies, and therefore reality, in the chaos of events is due to a direct connection between ultimate reality, namely God, and the mind of man.

In an early letter, Kepler opens to our view this main spring of his life's work:

"May God make it come to pass that my delightful speculation [the Mysterium Cosmographicum] have everywhere among reasonable men fully the effect which I strove to obtain in the publication, namely that the belief in the creation of the world be fortified through this external support, that thought of the creator be recognized in its nature, and that his inexhaustible wisdom shine

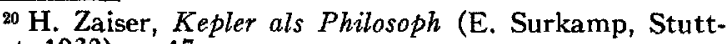
gart, 1932), p. 47. 
forth daily more brightly. Then man will at last measure the power of his mind on the true scale, and will realize that God, who founded everything in the world according to the norm of quantity, also has endowed man with a mind which can comprehend these norms. For as the eye for color, the ear for musical sounds, so is the mind of man created for the perception not of any arbitary entities, but rather of quantities; the mind comprehends a thing the more correctly the closer the thing approaches toward pure quantity as its origin." 21

On a superficial level, one may read this as another repetition of the old Platonic principle ò $\vartheta \epsilon \dot{\omega} s \dot{a} \epsilon \dot{i} \gamma \epsilon \omega \mu \epsilon \tau \rho \epsilon \tilde{i}$; and of course Kepler does believe in "the creator, the true first cause of geometry, who, as Plato says, always geometrizes" (Harmonice Mundi, Book 3). Kepler is indeed a Platonist, and even one who is related at the same time to both neo-Platonic traditions, -which one might perhaps better identify as the neo-Platonic and the neo-Pythagorean-, that of the mathematical physicists like Galileo, and that of the mathematical mysticism of the Florentine Academy. But Kepler's God has done more than build the world on a mathematical model; he has also specifically created man with a mind which "carries in it concepts built on the category of quantity," ${ }^{1}$ - in order that man may direcily communicate with the Deity:

"Those laws [which govern the material world] lie within the power of understanding of the human mind; God wanted us to perceive them when he created us in His image in order that we may take part in His own thoughts .... Our knowledge [of numbers and quantities] is of the same kind as God's, at least insofar as we can understand something of it in this mortal life." 22

${ }^{21}$ Letter to Mästlin, April 19, 1597. (Italics supplied.) The "numerological" component of modern physical theory is in fact a respectable offspring from this respectable antecedent. For example, see Niels Bohr, Atomic Theory and the Description of Nature (The Macmillan Company, New York, 1934), pp. 103-104: "This interpretation of the atomic number [as the number of orbital electrons] may be said to signify an important step toward the solution of one of the boldest dreams of natural science, namely, to build up an understanding of the regularities of nature upon the consideration of pure number."

${ }_{22}^{2}$ Letter to Mästlin, April 9/10, 1599. Galileo later expressed the same principle: "That the Pythagoreans had
The procedure by which one apprehends harmonies is described quite explicitly in Book 4, Chapter 1 of Harmonice Mundi. There are two kinds of harmonies, namely those in sense phenomena, as in music and in "pure" harmonies such as are "constructed of mathematical concepts." The feeling of harmony arises when there occurs a matching of the perceived order with the corresponding innate archetype (archetypus, Urbild). The archetype itself is part of the mind of the God, and was impressed on the human soul by the Deity when He created man in His image. The kinship with Plato's doctrine of ideal forms is clear. But whereas the latter, in the usual interpretation, are to be sought outside the human soul, Kepler's archetypes are within the soul. As he summarizes at the end of the discussion, the soul carries "not an image of the true pattern [paradigma], but the true pattern itself . . . . Thus finally the harmony itself becomes entirely soul, nay even God." ${ }^{23}$

This, then, is the final justification of Kepler's search for mathematical harmonies. The investigation of nature becomes an investigation into the thought of God, Whom we can apprehend through the language of mathematics. Mundus est imago Dei corporea, just as, on the other hand, animus est imago Dei incorporea. In the end, Kepler's unifying principle for the world of phenomena is not merely the concept of mechanical forces, but God, expressing himself in mathematical laws.

\section{KEPLER'S TWO DEITIES}

A final brief word may be in order concerning the psychological orientation of Kepler. Science, it must be remembered, was not Kepler's original destination. He was first a student of philosophy

the science of numbers in high esteem, and that Plato himself admired human understanding and thought that it partook of divinity, in that it understood the nature of numbers, I know very well, nor should I be far from being of the same opinion." Dialogue on the Great World Systems, p. 14. Descartes remark "You can substitute the mathematical order of nature for 'God' whenever I use the latter term" stems from the same source.

23 For a discussion of Kepler's mathematical epistemology and its relation to neo-Platonism, see Max Steck, "Über das Wesen des Mathematischen und die mathematische Erkenntnis bei Kepler, " in Die Gestalt, (Niemeyer, Halle, 1941), Vol. 5; the useful material is partly buried under nationalistic oratory. Another interesting source is A. Speiser, Mathematiche Denkweise (Birkhäuser, Basel, 1945). 
and theology at the University of Tübingen; only a few months before reaching the goal of a church position, he suddenly-and reluctantlyfound himself transferred by the University authorities to a teaching position in mathematics and astronomy at Graz. A year later, while already working on the Mysterium Cosmographicum, Kepler wrote: "I wanted to become a theologian; for a long time I was restless: Now, however, observe how through my effort God is being celebrated in astronomy." 24 And more than a few times in his later writings he referred to astronomers as priests of the Deity in the book of nature.

From his earliest writings to his last, Kepler maintained the direction and intensity of his religio-philosophical interest. His whole life was one of uncompromising piety; he was incessantly struggling to uphold his strong and often nonconformist convictions in religion as in science. Caught in the turmoil of the counter-reformation and the beginning of the Thirty Years' War, in the face of bitter difficulties and hardships, he never compromised on issues of belief. Expelled from communion in the Lutheran Church for his unyielding individualism in religious matters, expelled from home and position at Graz for refusing to embrace Roman Catholicism, he could truly be believed when he wrote, "I take religion seriously, I do not play with it," "In all science there is nothing which could prevent me from holding an opinion, nothing which could deter me from acknowledging openly an opinion of mine, except solely the authority

${ }^{24}$ Letter to Mästlin, October 3, 1595

${ }^{25}$ Letter to Herwart, December 16, 1598. of the Holy Bible, which is being twisted badly by many."26

But as his work shows us again and again, Kepler's soul bears a dual image on this subject too. For next to the Lutheran God, revealed to him directly in the words of the Bible, there stands the Pythagorean God, embodied in the immediacy of observable nature and in the mathematical harmonies of the solar system whose design Kepler himself had traced,- - a God "whom in the contemplation of the universe I can grasp, as it were, with my very hands." 27

The expression is wonderfully apt: so intense was Kepler's vision that the abstract and concrete merged. Here we find the key to the enigma of Kepler, the explanation for the apparent complexity and disorder in his writings and commitments. In one brilliant image, Kepler saw the three basic cosmological models superposed; the universe as physical machine, the universe as mathematical harmony, and the universe as central theological order. And this was the setting in which harmonies were interchangeable with forces,-in which a theocentric conception of the universe led to specific results of crucial importance for the rise of modern physics.

\footnotetext{
${ }^{26}$ Letter to Herwart, March 28, 1605. If one wonders how Kepler resolved the topical conflict concerning the authority of the scriptures versus the authority of scientific results, the same letter contains the answer: "I hold that we must look into the intentions of the men who were inspired by the Divine Spirit. Except in the first chapter of Genesis concerning the supernatural origin of all things, they never intended to inform men concerning natural things." This view, later associated with Galileo, is further developed in Kepler's eloquent introduction to the Astronomia Nova. The relevant excerpts were first translated by Thomas Salusbury, Mathematical Collections (London, 1661), Part I, pp, 461-467.

${ }_{27}$ Letter to Baron Strahlendorf, October 23, 1613.
}

\section{Chesapeake Section}

The Chesapeake Section of the American Association of Physics Teachers today announced the inauguration of a Scholarship Awards Program under which ten colleges and universities will award a total of thirteen scholarships to high school seniors in Delaware, Maryland, Virginia, and the District of Columbia. Scholarship winners will be determined by a competitive examination to be given on Saturday, May 5, at six test centers. The total value of the scholarships is in excess of $\$ 18,000$.

Colleges and universities awarding scholarships under the program are: Goucher College, Johns Hopkins University, Morgan State College, the University of Maryland, and Western Maryland College in Maryland; Georgetown University in the District of Columbia; and Hampton Institute, Madison College, Roanoke College, and Virginia State College in Virginia. Test centers will be located at the University of Delaware, Johns Hopkins University, George Washington University, University of Richmond, Roanoke College, and the Norfolk Division of the College of William and Mary.

The program was developed to help alleviate the current shortage of scientists and is under the chairmanship of Dr. Bernard B. Watson of the Operations Research Office of Johns Hopkins University. 